\title{
Transradial Versus Transfemoral Coronary Angiography
}

\author{
Amir Farhang Zand Parsa \\ Additional information is available at the end of the chapter \\ http://dx.doi.org/10.5772/54077
}

\section{Introduction}

Although trans-brachial approach via brachial cut done, that has been introduced by Sones in 1959, was the prefer method for coronary angiography in the 1950s and 1960s, because of the complexity of the procedure, it lost its popularity during last decades. Meanwhile trans-femoral (TF) approach became popular and dominant method for catheterization and angiography, because of the simplicity of the technique and operatorfriendly. Whereas trans-radial (TR) approach in aortography for the first time was reported by Radner S, in 1948 [1], due to small vessel size, this technique has been abandoned until 1989, that Campeau did relive this technique and introduced it as an ideal approach for coronary angiography [2]. Although TF approach still is dominant approach worldwide, during the last decade TR approach has emerged as a new method for coronary angiography and angioplasty, mostly in European countries and Japan. Because of its advantages, less vascular complication and early mobilization of patients, TR approach is going to be the method of choice for cardiac catheterization and angiography. TR technique encompasses vast majority of procedures, including diagnostic and interventional procedures, and suitable for most patients.

There is no doubt that all three above mentioned approaches are applicable in invasive and interventional cardiology but we are looking for the most feasible and safest approach for vascular access for coronary angiography and intervention.

The purpose of this chapter is to compare the different approaches in coronary angiography and intervention regarding their applicability, feasibility and safety. 


\section{Anatomical considerations}

Operators should be prepared for these approaches theoretically. The knowledge of anatomy of the femoral, brachial and radial arteries is necessary and helpful for doing these techniques successfully.

Femoral Access: Common femoral artery is the continuation of external iliac artery. It begins just below the inguinal ligament outside the femoral vein and inside to the femoral nerve. Common femoral artery and vein enclosed in a fibrous sheath that has been called, femoral sheath. It lies anterior and adjacent to the one third of internal aspect of the head of femur and crosses to the median side of the body of the femur (figure 1, A). One of the reasons that TF approach is prone to more complication is its proximity to the femoral nerve, femoral vein and pelvic cavity. Because puncturing of superficial femoral artery is more susceptible to pseudo-aneurysm, common femoral artery (first 3 centimeter) must be chosen for arterial puncture.

Radial access: The radial artery is the continuation of the brachial artery. It begins at the bifurcation of the brachial artery in the cubital fossa, and passes along the radial side of the forearm to the wrist toward the styloid process of the radius [3]. Then it passes between the two heads of the first Interosseous dorsalis into the palm of the hand (figure 1, B). At the wrist where arterial puncture should be done there is no nerve, vein or cavity at the vicinity of the radial artery, i.e. they are not enclosed in the same fibrous sheath. Deep palmar arch is a connection between the radial and the ulnar artery that protect hand from ischemia due to the occlusion of each branches. The radial artery serves mainly as an arterial conduit to the hand [4]. These are the reasons that radial approach is less prone to complication. The radial artery diameter is about $3.1 \mathrm{~mm} \pm 0.2 \mathrm{~mm}$ [5]. However, its size is variable and depends on patients' race, gender and size.

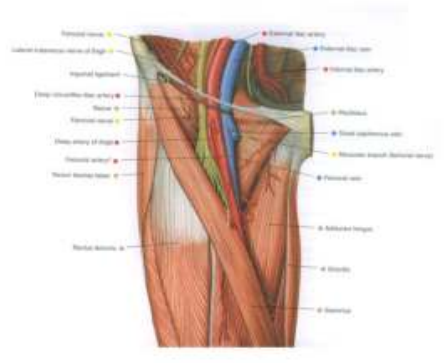

A

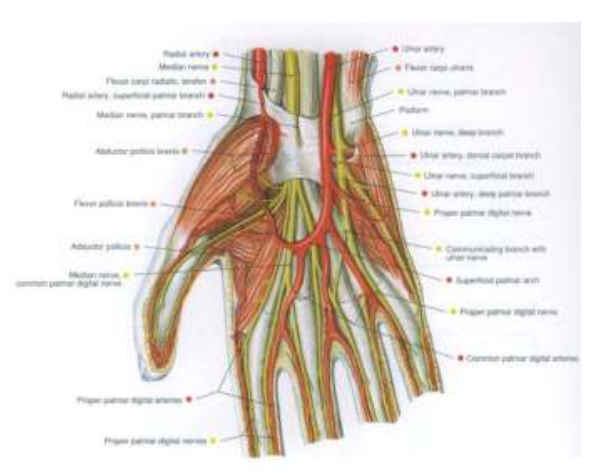

B

Figure 1. A; The femoral artery, femoral vein and femoral nerve at the groin, $B$; The radial and the ulnar arteries at the wrist (adapted from: R. Putzand, R. pubast, Sobotta Atlas of Human Anatomy, Urban \& Fisher, 14 ${ }^{\text {th }}$ edition, 2008, p. $245,614)[6]$ 


\section{Technical aspects}

Awareness of operators of instruments and devices (catheters, wires and etc....) compatible with each approach and method is crucial for doing these procedures successfully.

Arterial puncture: For doing catheterization and angiography the most important job is to find an accesses route. All cardiologists and interventionists are familiar with the transfemoral access. It is a large caliber artery and easy to be punctured and it is the advantage of this rout over the transbrachial or transradial approach. The only point that should be mentioned regarding TF approach is that the arterial puncture must be done in the groin not farther than 3 centimeter $(\mathrm{cm})$ from the inguinal ligament.

The most difficulty in the transradial technique that operators confront with is the arterial puncture and almost always it is responsible for the failure of the procedure. This is the main reason that this technique needs more experience. Learning curve in this technique dose has profound impact on the procedural success rate and procedural time [7, 8]. Access to the radial artery is a challenging job and needs learning curve for getting skill and to be expert.

Before trying to do radial puncture, it is necessary to do Allen's test for making sure that ulnar artery is patent and collateral supply of the hand is sufficient. The Allen's test for the first time was described by Dr.Allen in 1929 to evaluate collateral circulation of patients suffering from thromboangitis obliterans [9]. For this purpose the patient will be asked to clench his/her hand. Meanwhile operator compresses both the radial and the ulnar arteries by thumb fingers and again the patient will be asked to open his/her hand. After a few second compression on the ulnar artery will be released. In normal situation red color of finger tips will be restored within 10 seconds (positive Allen's test). Pulse Oxymetery of fingers is an alternative method. The test considered positive if the pulse waveform reappeared after releasing compression on the ulnar artery while compressing the radial artery (figure 2) $[10,11]$. However the necessity of the evaluation of collateral blood flow to the hand before TR approach is controversial [12].

Before doing radial puncture, the wrist should be prepared by hyperextending it over an arm board or positioned the arm beside the body with the wrist expanded. Sterilization with betadine must be done from elbow to the tips of fingers. Then the skin of the area is anaesthetized with $2-3 \mathrm{ml}$ lidocain $1 \%-2 \%$. The puncture site is approximately $1-2$ centimeter proximal to the radial styloid.

After identifying the radial artery a small incision of the skin of the prepared puncture site is done, and then the radial artery is punctured with a 20-21-gauge (G) needle through the incision. Appearances of pulsatile flow from the end of the needle confirmed that the needle is inside the lumen of the artery. It can be occurred when the needle is pushing inside the radial artery or when the needle that deeply seated in the posterior wall of the artery is pulling back until pulsatile flow from the needle reappears. Then a $0.018-0.035$ - inch hydrophilic guide wire is introduced through the needle for inserting 5 to 6- French (Fr), 11-25- $\mathrm{cm}$ long sheath in the radial artery (figure 3). Just after the insertion of a sheath, a cocktail consisted of $2 \mathrm{mg}$ verapamil, 100 microgram 
( $\mu \mathrm{gr}$ ) nitroglycerin and 2500 unit unfractionated heparin (UFH) or $200 \mu \mathrm{gr}$ nitroglycerin and 2500 unit UFH should be administered through the side arm of the sheath, for preventing vasospasm and thrombus formation. Right radial artery was preferred rout by the majority of operators so far but recently left radial artery has been introduced by some operators as a preferred method.

Although conventional catheters (pigtail, judkin's (left and right), XB, EB and etc....) can be used for catheterization and coronary angiography via radial access, usually new catheters such as Tiger (terumo) are used for coronary angiography (figure 3). The advantage of new catheters is that both left and right coronary arteries can be opacified by one catheter.

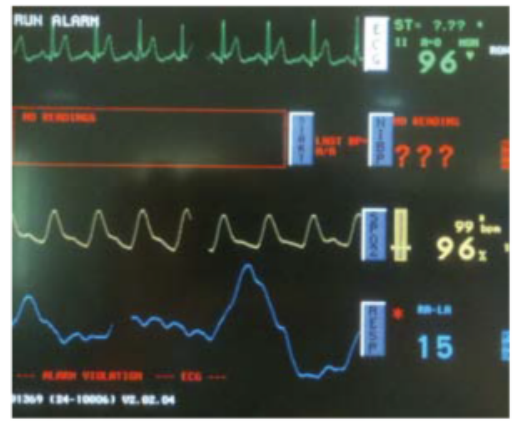

A

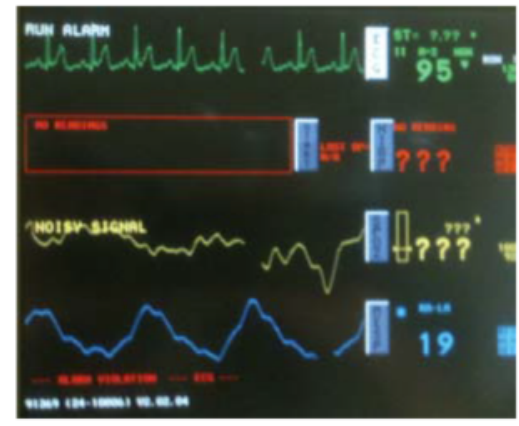

B

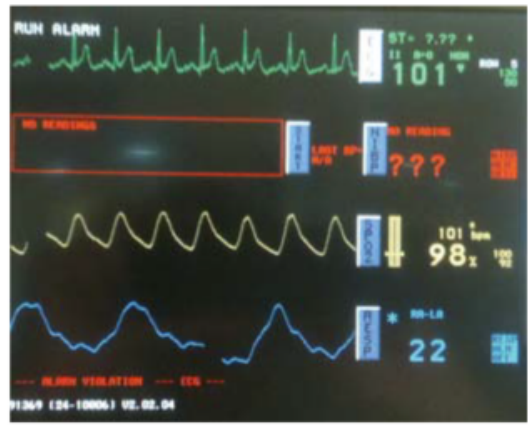

$\mathrm{C}$

Figure 2. Pulse waveform and oxygen saturation before (A), during (B) and after (C) Allen's test. (Adapted from: Natarajan D. Coronary Angiography - The Need for Improvement in Medical and Interventional Therapy. Edited by Branislav Baškot, Publisher: InTech, 2011; $p=55)$ [13] 


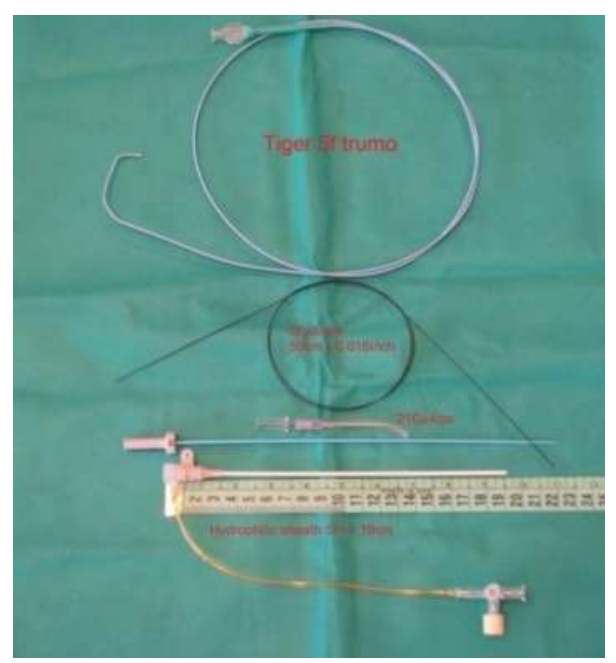

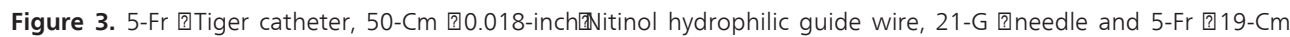
sheath, from top to below respectively.

\section{Limitations of each approach}

Transbrachial approach: The transbrachial approach that for the first time was introduced by F Mason Sones in 1958 has been done via arteriotomy (cut done) technique [14, 15]. Due to the complexity of the procedure this approach lost its popularity and no longer has been used as a routine approach for coronary angiography and intervention. However in recent years this approach is used for selected cases (in the presence of severe peripheral vascular disease and ect...) percutaneously. But the dominant approaches are either radial or femoral approach.

Transfemoral approach: Transfemoral approach that was introduced by Sven Ivar Seldinger in 1953 has been done percutaneously, figure 4 [16]. Because Seldinger's method was feasible and easy to do, very soon did get popularity among invasive and /interventional cardiologists and radiologists. For more than 50 years it has been the method of choice for angiography and/ angioplasty worldwide.

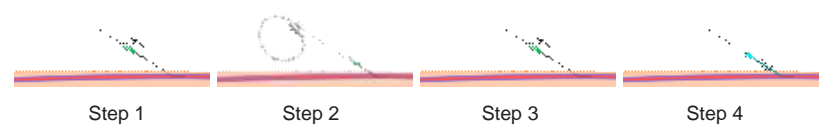

Figure 4. Steps of percutaneous technique for coronary angiography, Seldinger's method. (from Seldinger SI. Catheter replacement of the needle in percutaneous arteriography. A new technique. Acta Radiologica 1953; 39: 368-76) [16]. 
Limitations for TF approach are: 1) severe peripheral vascular disease, 2) obese patients, 3) presence of severe musculoskeletal abnormalities such as spine or hip malformation, 4) coagulopathies or patients who received high doses of anticoagulation. Not only these limitations decrease the success rate of procedures but also increase the complication rates that will be discussed later.

Transradial approach: Since the first time in1989 that Campeau L reported 100 cases of coronary angiography via getting access through the radial artery without major complication [2] and in 1993 that Ferdinand Keimeneij and colleagues did percutaneous coronary angioplasty (PTCA) by TR approach, that was comparable with TF approach, TR approach emerged as a new technique for coronary angiography and angioplasty. In 1997 Ferdinant Keimeneij et al,reported comparison between transradial, transbrachial and transfemoral PTCA in 900 patients. Although in their study access failure in TR approach was more common than transbracial and TF approaches, major access site complication were more frequent in the two latters [17]. However, with getting more experience the rate of failure in the TR approach has declined significantly [18]. Indeed transradial success rate depends to the operator learning curve.

TR approach is suitable for most patients and limitation of this approach is very low; however, there is some limitations for this approach that are as below: 1) inadequate ulnar artery collateral circulation (abnormal Allen's test), 2) needs for using large sheath, catheter and / devices, 3) the other limitation of this approach is need for repeating the procedure; however, it has been reported by Sakai and colleagues that transradial approach can be repeated for three to five times in the same access site, especially in men [19]. 4) The other limitation is the need for right heart catheterization and / endomyocardial biopsy simultaneously. However, some studies proposed forearm vein for right heart catheterization in the same time [20, 21].

\section{Complications}

Usually complications are vascular and mostly dependent to the access site. Although access site complication is more common in the TF approach compared to TR approach, it can occur in both approaches. These complications are:

1. Bleeding and hematomas; the most common complications in these approaches are bleeding and hematomas and their occurrence increase in the setting of anticoagulant and antiplatelet therapy that is usual in these patients. Bleeding complication in the femoral approach in the era of intervention is about 3\% that $1 \%$ of them need blood transfusion; however, in the radial approach it is nearly $0 \%[22,17]$. Keimeneij et al in a randomized study involving 900 patients did compare TF, transbrchial and TR approaches in patients undergoing percutaneous coronary intervention. In their study access site complications were significantly lower in the TR approach (Major access site bleeding occurred in seven patients $(2.3 \%)$ in the transbrachial group, six $(2.0 \%)$ in the transfemoral group and none in the transradial group, $\mathrm{p}=0.035$ [17]. A systematic review of randomized trials has shown reduction of access site complications by $73 \%$ when TR approach was employed instead of TF approach. In this met-analysis major 
bleeding occurred in $13(0.05 \%)$ of 2,390 patients in the radial access group compared to $48(2.3 \%)$ of 2,068 patients in the femoral access group (OR 0.27, 95\% CI 0.16-0.45; $\mathrm{P}<0.001$ ), figure 5 [23]. Also according to this meta-analysis of trials occurrence of haematomas was significantly lower in the radial access group compared with femoral access group (HR 0 40, 95\% CI 0 28-0 57; p<0 0001) [23].

2. Pseudoaneurysm; pseudoaneurysmcan is a potentially life threatening complication that particularly occurred in the TF approach. Its incidence in the TF approach was about $0.03 \%$ to $0.2 \%$ [24]. But it seems to be more prevalent in the era of intervention. Although in the above mentioned meta-analysis, that included all trials of percutaneous coronary intervention, few cases [7 0f 3507 patients) in the radial group has been reported [23], its incidence in the TR approach in coronary angiography is near zero.

Anticoagulation is the main risk factor for occurring pseudoaneurysm that followed by; receiving thrombolytic agents or potent antiplatelet ( $\mathrm{Gp}$ IIb/IIa), obesity, female gender, large sheath size, interventional procedures and multipuncture of the left groin. Although the size of the pseudoaneurysm is not an absolute predictor of the need for surgical repair, pseudoaneurysm smaller than $18 \mathrm{~mm}$ in diameter is safe and will be closed spontaneously. Ultrasoundguided compression is the first choice treatment of this complication.

\section{Major bleeding}

$\begin{array}{lccc}\text { Study name } & & & \\ \text { Radial } & \text { Femoral } & \begin{array}{c}\text { Peto } \\ \text { odds ratio }\end{array} \\ \text { ACCESS } & 0 / 300 & 4 / 300 & 0.13 \\ \text { Achenbach } & 0 / 152 & 4 / 155 & 0.14 \\ \text { Bodi } & 3 / 666 & 7 / 332 & 0.19 \\ \text { BRAFE } & 0 / 50 & 1 / 55 & 0.15 \\ \text { FARMI } & 3 / 57 & 3 / 57 & 1.00 \\ \text { Gorge } & 1 / 214 & 1 / 216 & 1.01 \\ \text { Mann 1998 } & 0 / 68 & 2 / 77 & 0.15 \\ \text { OCTOPLUS } & 1 / 192 & 7 / 185 & 0.21 \\ \text { OUTCLAS } & 0 / 322 & 1 / 322 & 0.14 \\ \text { RADIALAMI } & 1 / 25 & 4 / 25 & 0.27 \\ \text { RADIAMI } & 3 / 50 & 7 / 50 & 0.41 \\ \text { TEMPURA } & 0 / 77 & 2 / 72 & 0.12 \\ \text { Vazquez-Rodriguez } & 1 / 217 & 5 / 222 & 0.27 \\ & 13 / 2390 & 48 / 2068 & 0.27 \\ & & & \end{array}$

\section{OR $0.27(95 \%$ CI $0.16,0.45) P<.001$}

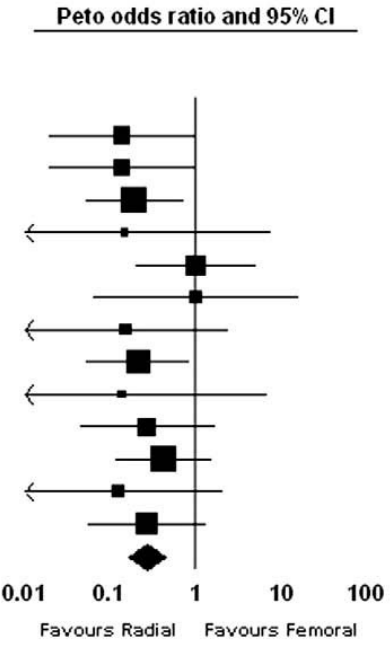

Figure 5. Forest plot for major bleeding of radial versus femoral access. (from; Jolly SS, Amlani S, Haman M, Yusuf S, Mehta SR. Radial versus femoral access for coronary angiography or intervention and the impact on major bleeding and ischemic events: A systematic review and meta-analysis of randomized trials. Am Heart J 2009;157:132-40) [23]

3. Arteriovenous fistula; Occurrence of arteiovenous fistula (AVF) after catheterization is more infrequent than pseudoaneurysm and such as other vascular access complications 
is more common in the TF approach. Its incidence in the femoral access site particularly in the era of interventional procedures according to some studies is about $0.3 \%$ to $0.8 \%$ $[25,26]$. Although occurrence of AVF is very rare in the TR approach, there is sporadic case report of its occurrence after using radial access for coronary angioplasty but not in diagnostic coronary angiography. In my best knowledge four cases of AVF after TR approach for intervention have been reported, table 4 [27]. Interestingly majority of catheter induced AVFs, either in the femoral access site or in the radial access site are asymptomatic.

4. Arterial occlusion is the most important but rare access site complication that more frequently occur in the TR approach. Radial artery occlusion has been reported $2 \%-60 \%$ in the studies using absence of pulse as a criterion for arterial occlusion [28], and 3\%-6\% in the studies using Doppler ultrasound findings [29]. Also Keimeneij et al reported 5\% radial artery occlusion at discharge and 3\% at one month follow up in their cases without any femoral artery occlusion [17]. Usually radial artery occlusion does not associate with ischemic complication. Duel arterial supply of the hand increases the safety of this procedure regarding thrombotic or traumatic occlusion of the radial artery. Generally speaking, the incidence of ischemic damage to the hand following TR approach is much lower and more infrequent compare to TF approach.

\begin{tabular}{|c|c|c|c|c|c|c|c|}
\hline & Authers & Year & Age/Sex & Lession \& site & Symptom or sign & Diagnostic tool & $\begin{array}{l}\text { Surgical } \\
\text { repair }\end{array}$ \\
\hline Case 1 & $\begin{array}{l}\text { Pulikal et } \\
\text { al }\end{array}$ & 2005 & $64 /$ male & $\begin{array}{l}\text { AVF of Rt radial } \\
\text { artery }\end{array}$ & $\begin{array}{l}\text { 1-Venous dilation \& } \\
\text { palpable thrill at } \\
\text { puncture site }\end{array}$ & $\begin{array}{l}\text { Doppler } \\
\text { ultrasound } \\
\text { imaging }\end{array}$ & yes \\
\hline Case 2 & $\begin{array}{l}\text { Spence et } \\
\text { al }\end{array}$ & 2007 & $59 /$ male & $\begin{array}{l}\text { Radial artery } \\
\text { pseudoaneurysm }\end{array}$ & $\begin{array}{l}\text { Painless pulsatile mass } \\
\text { at puncture site }\end{array}$ & $\begin{array}{l}\text { Doppler } \\
\text { ultrasound } \\
\text { imaging }\end{array}$ & yes \\
\hline Case 3 & $\begin{array}{l}\text { Spence et } \\
\text { al }\end{array}$ & 2007 & $61 /$ male & $\begin{array}{l}\text { AVF of radial } \\
\text { artery }\end{array}$ & $\begin{array}{l}\text { Painless pulsatile mass } \\
\text { at puncture site }\end{array}$ & $\begin{array}{l}\text { Doppler } \\
\text { ultrasound } \\
\text { imaging }\end{array}$ & yes \\
\hline Case 4 & Kwac et al & 2010 & $67 /$ male & $\begin{array}{l}\text { AVF of radial } \\
\text { artery }\end{array}$ & $\begin{array}{l}\text { Pulsatile mass \& thrill } \\
\text { at puncture site }\end{array}$ & $\begin{array}{l}\text { Doppler } \\
\text { ultrasound } \\
\text { imaging }\end{array}$ & yes \\
\hline
\end{tabular}

Table 1. Some cases which developed radial arteriovenous fistula after cardiac catheterization (adapted from: Kwac MS, Yoon SJ, Oh SJ, Jeon DW, Kim DH, and Yang JY. A rare case of radial arteriovenous fistula after coronary angiography. Korean Circ J 2010;40:677-79) [23]

AVF: arteriovenous fistula, Rt: right

5. Nerve injury; because of superficial course of radial artery and being far from nerve, in contrast to femoral artery (figure 1), nerve injury is more infrequent in TR approach compare to TF approach. 
Although as randomized trials did reveal significant reduction of access site complication by using TR approach [23], many invasive and/ interventional cardiologist do perceive that the decrease in vascular complications with TR approach are balanced by technical difficulties and increased radiation exposure with TR approach.

\section{Procedural duration and success rate}

As a whole TR approach was associated with a little bit longer procedural duration compare to TF approach, but in the hand of expert operators there was no significant difference (12.4 $\pm 5.8 \mathrm{~min}$ versus $11.2 \pm 3.3 \mathrm{~min})$, CARAFE study [7]. In the recent study that has been done by Bruek et al that was larger than CARAFE study and involved operators who were in their early learning curves of TR approach [8]. The median procedural duration for TR and TF approaches were $40.2 \mathrm{~min}$ and $37 \mathrm{~min}$ respectively, that difference was statistically significant $(\mathrm{p}=0.046)$. Also in a meta-analysis of randomized trials that has been done by Jolly et al, TR approach was associated with longer procedural duration, when weighted mean difference, 3.1 minutes (95\% CI 2.4-3.8 $\mathrm{p}<0.001)$. When comparing non-radial expert $(4.8 \mathrm{~min}, 95 \% \mathrm{CI}$ $3.7-5.8 \mathrm{~min})$ to radial expert $(1.7 \mathrm{~min}, 95 \% \mathrm{CI} 07-2.6 \mathrm{~min})$, there is significant heterogeneity [23]. It means that operator experience plays a major role in the procedural duration for TR approach.

Usually procedural success rate in the TR approach is less than TF approach that generally is due to failed radial puncture. The success rate (successful angiography without occurrence of significant hematomas) for TR approach compare to TF approach in the Bruek et al, study [8] was $96.5 \%$ versus $99.8 \%$ respectively $(p<0.0001]$. However, recent studies revealed no significant difference in procedural success rate between two techniques [30].

Age didn't have any impact on procedural success rate on the TR approach. Procedural success in patient older than and younger than 70 years old was the same [95.1\% versus $94.8 \%$ respectively, $\mathrm{p}=\mathrm{NS}$ ) [31]. Also there was no significant difference in the procedural success rate in patients who had prior brachial arteriotomy (cut-down) and those who didn't $[93.6 \%$ versus 95.3\% respectively, $\mathrm{p}=\mathrm{NS}$ ) [18].

\section{Advantages and disadvantages of two techniques}

As mentioned above both techniques have advantages and disadvantages over each other.

Advantages of TF approach over TR approach are: i) because of large caliber vessel it provides easier access site canulation for inserting different sheath size, particularly, large lumen sheaths, that is necessary in the era of interventional cardiology for using large lumen catheters and/large caliber devices. ii) The other advantageous of this technique is that it made simultaneous venoul canulation possible. iii) It takes $\mathrm{X}$ ray tube far from operator, and iv) repeatable for unlimited and/several times. iiv) As a whole this technique was associated with higher procedural success rate particularly in the era of interventional cardiology. 
However; disadvantages of TF approach are: i) bleeding that is common in the setting of antiplatelet and anticoagulation therapy, that is usual in these patients, is the most important and prevalent complication of TF approach. Major bleeding results $>3$ fold increases in-hospital and one year mortality (odds ratio=3.5) and re-infarction [32]. ii) Pseudoaneurysm, atriovenous fistula and retroperitoneal hemorrhage are serious and life-threatening complication of this procedure. iii) Another disadvantageous of TF approach, albeit rare, is thromboembolic or ischemic events of lower extremities, that more often occurred in the presence of peripheral vascular disease or as a result of traumatization and/ dissection of iliac or illeofemoral arteries.

TR approach has gained popularity in recent years and is going to be the technique of choice in coronary angiography and even coronary intervention due to its advantages over TF approach.

The advantages of TR approach over TF approach are; i) reduction of vascular complications in terms of hematomas, bleeding and etc..., even in the setting of acute coronary syndrome (ACS) and/ in patients receiving antithrombotic and antiplatelet therapies. Due to achieving easy hemostasis the bleeding complication and need for transfusion have decreased dramatically by this technique compare to TF approach. In the MORTAL (Mortality Benefit of Reduced Transfusion after PCI via the Arm or Leg) TR approach was associated with $50 \%$ reduction in blood transfusion rate, and $29 \%$ and $17 \%$ reduction in 30-day and one year mortality respectively $(\mathrm{p}<0.001)$ [33]. Although in the RIVAL study TR approach was superior to TF approach regarding access site complications (bleeding, hematoma, pseudoaneurysm, etc...), and the incidence of access site complications even in the presence of aggressive anticoagulant regimen were negligible, they concluded that both techniques are safe and effective [34]. ii) Early ambulation and hospital discharge of patients, decreasing hospital cost and increasing patient comfort and satisfaction are other advantages of TR approach over TF approach. In a meta- analysis of more than 20 randomized trials [23], TR approach reduced hospital stay by 0.4 day (95\% CI 0.2-0.5, p=0.0001).

The most important disadvantages of TR approach are; the increasing radiation exposure of the operator, access failure and procedural failure, which is higher in comparison with the TF approach and absolutely depend to the operator's learning curve and skill.

\subsection{Post procedural hemostasis}

Because of the small size and superficiality of the radial artery, hemostasis can be achieved by manual compression. Usually the arterial sheath is removed at the catheterization laboratory at the end of procedure. Hemostasis is obtained by manual compression of the puncture site, and then compression is applied with a cotton pillow tourniquet or by using pressure bandage with elastic sticky straps. In any way the bandage is removed after 6 hours.

In the TF approach also the sheath is removed in the catheterization laboratory and hemostasis is obtained by manual compression, then a bandage and sandbag is applied proximal to the puncture site. The patient should be restricted to bed rest for at least 6 hours. In the case of extensive anticoagulation, vascular closure device can be used for hemostasis. However, in 
the presence of severe atherosclerosis and small diameter of the femoral artery closure device shouldn't be used.

\section{Summary}

Both transfemoral and transradial techniques are safe, feasible and comparable techniques for cardiac catheterization, angiography and intervention. However, each of these two techniques has own applications and limitations. Although TF approach is dominant approach worldwide, TR approach is going to be the technique of choice for coronary angiography and percutaneous coronary intervention in the near future. TR approach reduces hospital stay, procedural cost and vascular complications and also increases patients comfort and satisfaction. However, this approach needs more experience and greater learning curve compare to TF approach. In another word, TF approach is the easier and more operator-friendly technique for catheterization and angiography; but with substantial access site complications. On the other hand, TR approach is safer and more patient-friendly technique for catheterization and angiography but it needs more experience and higher learning curve.

Case selection is mater in this regard. For example obese patients, patients with severe peripheral vascular disease and / severe musculoskeletal abnormalities and patients with coagulopathies or under aggressive anticoagulation are not good candidate for TF approach. The prefer approach for these patients is TR approach. On the other hand patients with abnormal Allen's test, patients who need simultaneous right and left heart catheterization and when insertion of a large sheath is needed are not good candidate for TR approach. The prefer approach for these patients is TF approach. Indeed these two vascular access techniques can be reconciled.

\section{Author details}

Amir Farhang Zand Parsa

Imam Khomeini Hospital Complex, Tehran University of Medical Sciences, Tehran, Iran

\section{References}

[1] Rander S. Thoracal aortography by catheterization from radial artery; preliminary report of a new technique. Acta Radiol 1948; 29: 178-80

[2] Campeau L. Percutaneous radial artery approach for coronary angiography. Cathet Cardiovasc Diagn 1989; 16: 3-7 
[3] Karlsson S, Neichajev IA. Arterial anatomy of the upper extremity. Acta Radiol Diagn 1982; 23: 115-21

[4] Haerle M, Hafner HM, Dietz K, Schaller HE, Brunelli F. Vascular dominance in the forearm. Plast Reconstr Surg 2003;111: 1891-8

[5] Fazan VP, Borges CT, Dasilva JH, Caetano AG, Filho OA. Superficial palmar arch: an arterial diameter study. J Anat 2004; 204: 307-11

[6] Putzand R, pubast R. Sobotta ; Atlas of Human Anatomy, Urban \& Fisher, $14^{\text {th }}$ edition, 2008; p.245, 614

[7] Louvard Y, Lefevre T, Allain A, Morice M. Coronary angiography through the radial or the femoral approach: the CARAFE study. Cathet Cardiovasc Interv 2001; 52: 181-7

[8] Brueck M, Bandorski D, Kramer W, Wieczorek M, Holtgen R, Tillmans H. A randomized comparison trasradial versus transfemoral approach for coronary angiography and angioplasty. J Am Coll Cardiol 2009; 2: 1047-54

[9] Allen E. Thromboangitis obliterans: methods of chronic occlusive arterial lesions distal to the wrist with illustrative cases. Am J Med Sci 1929; 178: 237-44

[10] Benit E, Vranckx P, Jaspers L, Jackmaer TR, Poelmans C, Coninx R. Frequency of a positive modified Allen's test in 1000 consecutive patients undergoing cardiac catheterization. Cathet Cardiovasc Diagn 1996; 38: 352-4

[11] Barbeau G, Arcenault F, Dugas L, Lariviere M. A new and objective method for transradial approach screening. J Am Coll Cardiol 2001; 37: 34A-36A

[12] Slogoff S, Keats AS, Arlund C. On the safety of radial artery cannulation. Annesthesiology 1983; 59: 42-7

[13] Natarajan D. Coronary Angiography - The Need for Improvement in Medical and Interventional Therapy; Edited by Branislav Baškot, Publisher: InTech, Published: 2011; $\mathrm{p}=51-74$

[14] Sones FM Jr, Shirely EK. Cine coronary angiography. Mod Concepts Cardiovasc Dis 1962; 31: 735-8

[15] Proudfit WL, Shirely EK, Sones FM Jr. Selective coronary angiography. Correlation with clinical findings in 1000 patients. Circulation 1966; 33: 901-10

[16] Seldinger SI. Catheter replacement of the needle in percutaneous arteriography: a new thechnique. Acta Radiologica 1953;39: 368-76

[17] Kiemeniej F, Laarman GJ, Odekerken D, Slagboom T, Vanderwieken R. A randomized comparison of percutaneous transluminal coronary angiography by the radial, brachial and femoral approaches: the access study. J Am Coll Cardiol 1997; 29: 1269-75 
[18] Caputo RP, Simons A, Giambartolomei A, Grant W, Fedele K, Esente P. Transradial cardiac catheterization in patients with prior brachial artery cut down. Cathet Cardiovasc Interv 1999; 48: 271-4

[19] Sakai H, Ikeda S, Harada T, Yonashiro S, Ozumi K, Ohe H, et al. Limitations of successive transluminal approach in the same arm: the Japanese experience. Cathet Cardiovasc Interv 2001; 54: 204-8

[20] Moyer CD, Gilchrist IC. Transradial bilateral cardiac catheterization and endomyocardial biopsy: a feasibility study. Cathet Cardivasc Interv 2005; 64: 134-7

[21] Gilchrist IC, Moyer CD, Gascho JA. Transradial right and left heart catheterization: a comparison to traditional femoral approach. Cathet Cardiovasc Interv 2006; 67: $585-88$

[22] Rao SV, Eikelboom JA, Granger CB, Harrington RA, Callif RM, Bassand JP. Bleeding and blood transfusion issues in patients with non-ST- segment elevation acute coronary syndromes. Eur Heart J 2007; 28: 1193-204

[23] Jolly SS, Amlani S, Haman M, Yusuf S, Mehta SR. Radial versus femoral access for coronary angiography or intervention and the impact on bleeding and ischemic events: a systematic review and meta-analysis of randomized trials. Am Heart J 2009; 157: $132-40$

[24] Souka H, Burkenham T. Management plan of post-angiography false aneurysm of the groin. Ann Saudi Med 1999;19:101-5

[25] Kent KC, Mc Ardel CR, Kennedy B, Baim DS, Anninos E, Skillman JJ. A prospective study of the clinical outcome of femoral pseudoaneurysms and arteriovenous fistulas induced by arterial puncture. J Vasc Surg 1993;17:125:33

[26] Perings SM, Kelm M, Jax T, Strauer BE. A prospective study on incidence and risk factors of arteriovenous fistula following transfemoral cardiac catheterization. Int J Cardiol 2003; 88: 223-8

[27] Kwac MS, Yoon SJ, Oh SJ, Jeon DW, Kim DH, Yang JY. A rare case of radial arteriovenous fistula after coronary angiography. Korean Circ J 2010; 40: 677-79

[28] Stella PR, Keimeneij F, Laarman GJ, Odekerken D, Stagboom T, Vanderwieken R. Incidence and outcome of radial artery occlusion following transradial artery coronary angiography. Cathet Cardiovasc Diagn 1977; 40: 156-8

[29] Chen JY, Lo PH, Hung JS. Color doppler ultrasound evaluation of radial artery occlusion in transradial catheterization. Acta Cardiol Sin 2001; 17: 193-200

[30] Rao SV, Ou FS, Wang TY, Roe MT, Brindis R, Rumsfeld JS, Peterson ED. Trends in the prevalence and outcomes of radial and femoral approaches to percutaneous coronary intervention: a report from the national cardiovascular data registry. J Am Coll Cardiol 2008; 1: 379-86 
[31] Caputo RR, Simons A, Giambartolomei A, Grant W, Fedele K, Abraham S, Rejer MJ, Walford GD, Esente P. Transradial cardiac catheterization in elderly patients. Cathet Cardivasc Interv 2000; 51: 287-90

[32] Fei T, Voeltz MD, Attubato MI, Lincoff AM, Chew DP, Bittl JA, Topol EJ, Manoukian SV. Predictors and impact of major hemorrhage on mortality following percutaneous coronary intervention from Replace-2 trial. Am J Cardiol 2007; 100: 1364-69

[33] Chase AJ, Fretz EB, Warburton WP, Klinke WP, Carere RG, Pi D, Berry B, Hilton JD. Association of the arterial access sites at angioplasty with transfusion and mortality study (mortality benefit of reduced transfusion after percutaneous coronary intervention via the arm or leg). Heart 2008, 91: 1019-25

[34] Jolly SS, Yusuf S, Cairns J, Neimelä K, Xarier D, Widimsky p, Budaj A, Neimelä M, Valentin V, Lewis BS, Avezum A, Step PG, Rao SV, Gao P, Afzal R, Joyner CD, Chrolacius S, Mehta SR; RIVAL trial group. Radial versus femoral access for coronary angiography and intervention in patients with acute coronary syndrome (RIVAL): a randomized parallel group multicenter trial. Lancet 2011; 377:1409-20 